\title{
Applications of Soft Computing Techniques for Pulmonary Tuberculosis Diagnosis
}

\author{
Siraj Sebhatu, Ashok Kumar Sahoo, Pooja
}

\begin{abstract}
Recently, several interesting research studies have been reported on soft computing approaches. Soft computing approaches are solving several kinds of problems and provide alternative solutions. Different Soft computing techniques or approaches have been applied in medical care data for effective diagnosis prediction. Those approaches implemented on diseases diagnosing of pulmonary tuberculosis and obtaining better results in comparison to traditional approaches. This approach is an aggregation of methodologies that were combined various model and provide solutions to those problems that are difficult to handle in real-world situations. Researchers keep developing of an accurate and reliable intelligent decision-making method for the construction of pulmonary tuberculosis diagnosis system. The existing diagnostic testing system procedures are not only tedious, they also take a long time to analyze. Therefore, the diagnosis of tuberculosis still requires further improvements to new rapid and accurate diagnostic model and techniques that enable higher sensitivity and specificity to be achieved, thus promoting disease control and Prevention. State of the art makes approaches to soft computing more powerful, more reliable and more efficient. The importance of this review paper is to distinguish the different soft computing approaches used to support pulmonary tuberculosis disease diagnosis, identification, prediction and intelligent classification. In the field, researchers and medical practitioners look forward to using approaches to soft computing. Some of these are an artificial neural network, genetic algorithm, and support vector machine, fuzzy logic etc. latest methods in the diagnostic field uses artificial neural network. Some of the other benefits of Artificial neural network is an easy - to - optimize, resources and adoptable non - linear modeling of expansive data sets and predictive inference accuracy demonstrating that artificial neural network could serve as a valuable decision support tool in various fields, including medicine.
\end{abstract}

Index Terms: Artificial Neural Network, Fuzzy and Fuzzy Logic, Genetic Algorithm, Pulmonary Tuberculosis, Support Vector Machine.

\section{INTRODUCTION}

Tuberculosis is a bacterial infection causing more death than any other infectious disease in the world [1]. Overall, the World Health Organization reported that there were 10.4 Million new tuberculosis cases with related deaths in 1.4 million in 2015 such as India, Indonesia and China having the largest number of cases: $23 \%, 10 \%$ and $10 \%$ of total global

Revised Manuscript Received on October 22, 2019.

Siraj Sebhatu, Department of Computer Science \& Engineering, Sharda University / School of Engineering \& Technology / Organization Name, City Greater Noida, Uttar Pradesh, India,

Ashok Kumar Sahoo, His Department of Computer Science \& Engineering, Sharda University / School of Engineering \& Technology / Organization Name, City Greater Noida, Uttar Pradesh, India,.

Pooja, His Department of Computer Science \& Engineering, Sharda University / School of Engineering \& Technology / Organization Name, City Greater Noida, Uttar Pradesh, India. deaths, respectively [1], [2], [3] and [4], [5].

India is one of the 22 countries with a high burden. High-burden means that by 100,000 populations or more there are about 400 cases. In India, the World Health Organization estimated one million new TB cases per year and Every year 2,2 million individuals contracted tuberculosis and approximately 220,000 died of the disease [1][3]. Unfortunately, it detects only one-third of new cases of TB. The number shows a severe delay in treatment and diagnosis of TB. Long - term lung damage is associated with delayed treatment of PTB, often clinically mistaken for non tuberculosis pneumonia due to symptom similarities and presentation of chest $\mathrm{X}$ - ray (CXR) [6]. They reported that a delay in treatment of more than twelve weeks would result in a greater extent of patients with serious TB, a higher mortality rate, and a more prominent disappointment in treatment [7][8]. For some reasons [9] and [10], diagnosis of tuberculosis is difficult. For pediatric patients with a small number of germs, the first reason [11], [12]. For some reasons [9] and [10], diagnosis of tuberculosis is difficult. The first reason is for pediatric patients with a few germs [10]. The second is for extra - pulmonary tuberculosis [12], [13] and the third for smear - negative pulmonary tuberculosis (SNPT) [14], [15]. Cough, hemoptysis, night sweats, fever, and weight loss are the suggestive symptoms of TB [16]. These symptoms are not only common to lung cancer [8], but also to other diseases [17], [18]. It leads to delays in proper diagnosis and exposure to inappropriate medication [8] as well as misdiagnosis and death [16]. A longer delay in pulmonary tuberculosis diagnosis avoids quick treatment, and the person remains confined. Furthermore, people receiving inadequate treatment are more vulnerable to multidrug-resistant tuberculosis [19], [20]. To overcome these problems, some studies have been done. Studies related to TB diagnosis were conducted as input parameters using sound, images, blood microRNA profiles, and variables. Some studies that use coughing sound detection algorithm to accelerate the process of TB diagnosis with a high degree of accuracy [21] and [6] and using lung sound waves as specificity. The image of the tissue of tuberculosis was used in many studies as an input to help pathologists [3], [8].

A Recent study was conducted using blood miRNA profiles, and the model was also tested using urine and saliva miRNA [6]. Furthermore, soft computing methods to analyze tuberculosis utilizing clinical indications as input have been broadly utilized in numerous studies [22]. 
The objective of artificial intelligence (AI) is to imitate cognitive functions of humans. It brings a paradigm shift to healthcare, driven by increased healthcare data availability and rapid progress in analytical techniques [23], [24] and support to minimize complex subjective medical decisions. traditional quantitative analytical approaches inappropriate. Diagnostic tools and knowledge base based on computers certainly help to diagnose diseases early. The Smart systems also can handle inappropriate decision [25].

In the diagnosis of disease, these methods have been shown to be significant, facilitating the improvement of the quality of medical services. Soft computing techniques have attracted many medical diagnostic researchers for days now, and these techniques need to be characterized by high performance and ability to handle missing values and noisy data. Diagnostic systems handle a large quantity of biomedical data. Such a system's accuracy is an important aspect. In order to achieve accuracy, the classifier idea was adopted as different classifiers provide different views and their results are combined to achieve accuracy [25], [24].

To overcome these problems, some studies have been done. TB diagnostic studies were conducted using sound, images, and variables as parameters of input. In [6] and [3], some studies that use sound as an input are conducted. They used coughing sound detection algorithm [15] which uses lung sound waves to speed up the TB diagnosis process with high accuracy and specificity. However, nearly all feature extraction methods in previous works for cough detection are derived from the domain of speech recognition [3], [26]. Using the gamma tone filter bank and an audio feature extraction, the method used was sub-band features. Support Vector Machine (SVM), K-Nearest Neighbors (KNN) and Random Forest (RF) are trained and assembled with the relevant sub-band features [9].

However, datasets in health domain are highly imbalanced, voluminous, conflicting and complex in nature, and these can lead to erroneous diagnosis of diseases. It is therefore a challenging task in soft computing to design accurate and robust clinical diagnostic models for such datasets. Numerous standard intelligent models have been proposed for this purpose in literature, but they usually suffer from several disadvantages such as incomprehensibility, incapacity to operate rare cases, inefficiency to make quick and correct decisions, etc. [10], [27]. In fact, specific health application using standard intelligent methods may not satisfy multiple criteria [10], [24].

Recent research, however, indicates that intelligent methods can achieve better performance for health applications by integrating several standard ones [28]. Intelligent modeling is a growing need for data, as the amount of data stored in databases is increasing rapidly and the number of human data analysts is growing at a much lower rate than the amount of data stored and Machine learning is an excellent process to design these models [10]

Furthermore, doctor's intuition and experience are not always sufficient to achieve medical results of high quality. Therefore, medical errors and unwanted results are reasons for the need for state-of-the-art computer-based diagnostic systems that in turn reduce fatal medical errors, increase patient safety and save lives.

\section{SOFT COMPUTING METHODS FOR TUBERCULOSIS DIAGNOSIS}

The purpose of this study is to outline the relationship between different soft computing techniques and, in particular, the application of soft computing techniques to diagnosis and prediction of pulmonary tuberculosis diseases. This review therefore includes studies based on diagnosis of diseases and predictions using soft computing techniques.

Soft computing is an aggregation of methodologies for modeling and solving the problems that are onerous to deal with in real - world situations [29], [30]. To provide robustness and low - cost solutions, soft computing technique is introduced. The basic principle is to develop computational methods that lead to a satisfactory low-priced solution by exploring an indefinite or definite problem for the comparative solution [15], [24], [20], and [22]. Some soft computer techniques used to predict diseases are Fuzzy Logic, Artificial Neural Network and Genetic Algorithm [27].

Utilizations of delicate registering procedures in respiratory medicine are progressively suitable as they can deal with issues like nonlinearity, multidimensionality, and ambiguity contrasted with hard figuring, for example, probabilistic methodologies. Be that as it may, the number of research endeavors is lower because of the absence of accessibility of the joined area mastery. Information system researchers think that it is difficult to comprehend and demonstrating the infection, its portrayal and assessment. Then again, it is troublesome for respiratory prescriptions to understand the benefits of calculations, their coding and the important execution. Be that as it may, regardless of these obstructions, specialists have been making endeavors to screen and analyze respiratory illnesses utilizing delicate processing methods for a considerable length of time. In the accompanying segment, some ongoing examinations have been portrayed [6]. Medicinal basic leadership all in all is an intricate procedure with higher-dimensional, crude, and emotional clinical information being taken care of. Right choice requires an arrangement of the abnormal state observations and instincts of clinicians so as to comprehend a procedure of illness. Right determination relies upon the quantity of side effects coordinated with the reference sickness agents [6]. Manual conclusion is regularly individualized thus as the introduction of a disease. In this manner, the suitability of the term traditional ends up relative in clinical prescription. Uses of higher delicate figuring technique(s) and ideas of computational knowledge have huge research scopes in demonstrating the procedure of clinical finding because of its operational similarity. It likewise welcomes an open door for the cross-disciplinary research [31].

In addition, medical challenges are increasing gradually in developing countries such as India, [16]. 
Anyway right analysis of any illness depends on different, and typically ambiguous, information (highlights): for instance, laboratory pathologic assessment, lab and instrumental information, emotional anamnesis of the patient, and contemplations of the clinician. Clinicians are prepared to separate the significant data from each sort of information to distinguish conceivable analyses.

In conventional neural system application such information are designated "highlights". Highlights can be side effects, biochemical investigation information or potentially whichever other significant data helping in conclusion. Thusly, the experience of the expert is firmly identified with the last finding [10], [33].

Highlights that bring deficient, repetitive, non-explicit, or boisterous data about the examined issue ought to be kept away from. The determination/extraction of reasonable highlights among every accessible one is generally completed utilizing different methodologies. The most vital and best-known manipulating tools for variable determination are powerful scientific methods for data processing, for example, key parts principal of component analysis [9], [13] and [33].

\section{A. Fuzzy logic}

Fuzzy Logic (FL) used intelligence procedures that manages vulnerability in information and reproduces human thinking in an incomplete or fuzzy information [14]. It is an appropriate and pertinent reason for creating learning based system in differing parts of life, for example, wellbeing. It has been connected to translate sets of restorative discoveries and rule saves the structure of the justification and avoids escapes the logical inconsistency of component [14].

\section{B. Artificial Neural Network}

Artificial neural systems bio-driven intelligent framework, broadly connected to forecast, learning extraction of tasks and classification [10], [34].It trying to understand the intricacy of biological sensory system in order to concentrate on what may theoretically matter most from a data preparing perspective.

Medication has dependably profited in different territories of prescription, for example, biomedical examination, and medication advancement however widely utilized in determination to identify sicknesses, for example, disease and heart issues in human [34].

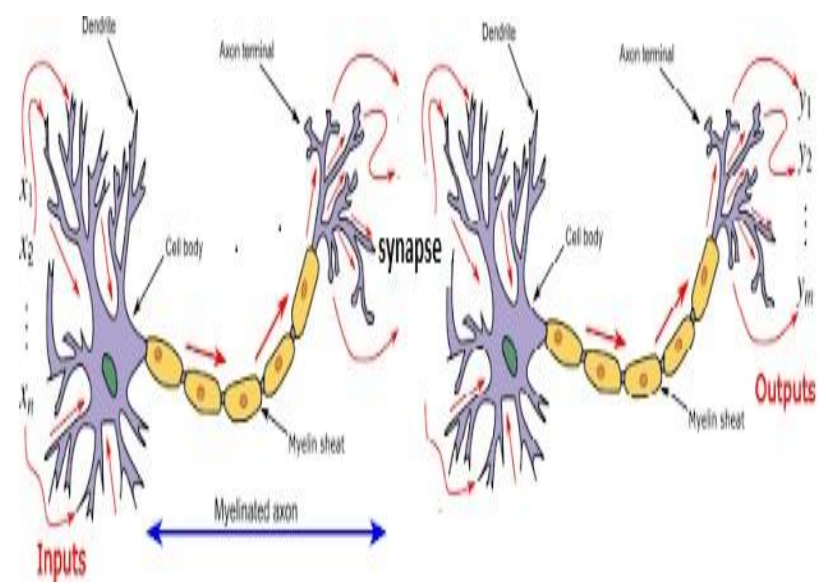

Fig. 1. Neural network Signal transmission between

\section{neuron}

\section{Multilayer perception}

Multilayer Perceptron (MLP) Neural network to classify active and inactive pulmonary tuberculosis of the patient. Several studies have proposed useful architecture to predict the outcome of disease and stratify patients [34]. Automatically extracts cases used to characteristic parameters and produces a decision based on the existing parameter and rule such as classification, based on supervised training process learner algorithms how to predict dataset labels. The model used to classified one hidden and output layer [33], [36] and [37].

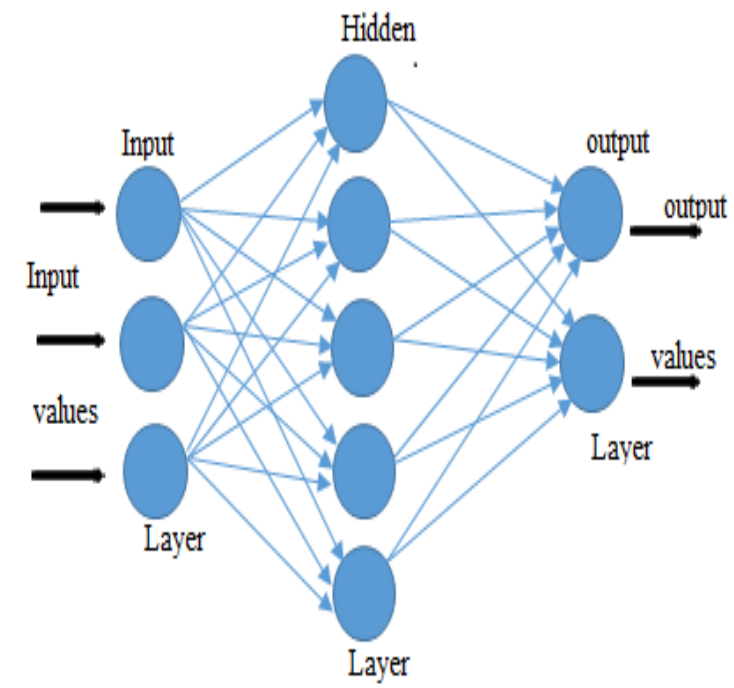

Fig. 2. Multilayer perceptron (MLP) neural network

The artificial neural network utilized in this work had an information layer made out of seven units, every one for every factor, and one yield layer made simply out of one neuron. Estimations of +1 and - 1 were utilized to speak to whenever input information relates to a patient with or without tuberculosis, individually. The hidden layer neuron was built up an exploratory way, testing from 2 to 10 neurons. All neurons had a hyperbolic digression work as enactment work. Between various learn to prepare the artificial neural network, [6], and [21] a cross-validation strategy was also considered in training. Training was conducted with two sets in each case (see Table IV) and validation results were calculated with the maximum classification rate between tuberculosis or not. An early stopping procedure has been implemented to avoid overfitting. The performance of the models obtained was evaluated using sensitivity, specificity, rates of classification, positive prediction and negative prediction measures as shown in Table III [37].

\section{Genetic algorithms}

A genetic algorithm is a technique for soft computing. It was used in the recognition of patterns, bioinformatics. In order to increase the chance of prosperous treatment, early detection of disease is very important. Soft computing techniques are used to identify a medical issue.

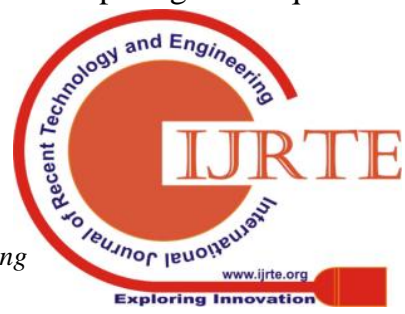


Such as genetic algorithm starts with a population of arbitrarily generated chromosomes. The current problem is solved by each chromosome [38], [39]. Improved chromosomes are achieved by applying genetic operators based on genetic processes that occur in nature. Because of its robust nature, the genetic algorithm had a good measurement performance finding and optimizing problems. It is developed specifically for large complex search spaces where [10], [27] and [39] are not well understood.

\section{CURRENTLY USED METHODS FOR PULMONARY TUBERCULOSIS DIAGNOSIS}

The most well-known attempts are intelligent classification systems. As neural models, conventional MLP and a variation were used and comparing their performance with two different data sets. The conventional MLP is better classification accuracy. [16], [17] and [40] some researchers compared several methods in order to study which method obtained the highest accuracy in diagnosing tuberculosis. [16], [17].

All these tests however have one of the main disadvantages because they are useless in distinguishing drug Resistance TB. It also takes time to evaluate outcomes and include invasive methods that are tedious to carry out some of the significant TB diagnostic tests. There have been several studies reported focusing on using different neural network models to diagnosis pulmonary tuberculosis disease achieved high classification accuracies using their various dataset [16], [21], [27], [33], [34] and [36].

In addition the intelligent methods such as artificial neural network have been intensively used for classification tasks and also both multilayer neural network and neural network structure successful disease diagnosis techniques [16],[27],[33],[34],[36].

Furthermore [41] the techniques used to analyze pulmonary tuberculosis (TB) disease using the neuro - fuzzy inference system are used as inputs for decision - making based on a predefined rule based on the patient's symptoms and the corresponding risk quotient for tuberculosis is evaluated as output and [41]. The result of crisp has also shown that we can diagnose the patient's low or high risk of disease [41]. Recently several neuro-fuzzy techniques have been reported in the literature [7], [9], [10] and [20] for classification of patterns.

Modern non-measurable pattern classifiers are mostly either expert rules-based systems or classifiers of artificial neural networks. Some attempts are made to integrate the two paradigms where neural networks are used to extract knowledge from raw data and to use approximate reasoning and fuzzy logic to perform inferencing. The most effective solution seems to be extracting knowledge from the raw data through artificial neural network and expressing it in a rule form to design the knowledge base of an expert system with a blurred inferencing method. But there are still many issues [20], [36] and [41] at various levels of designing such an intelligent classification system for real-world issues open to research.

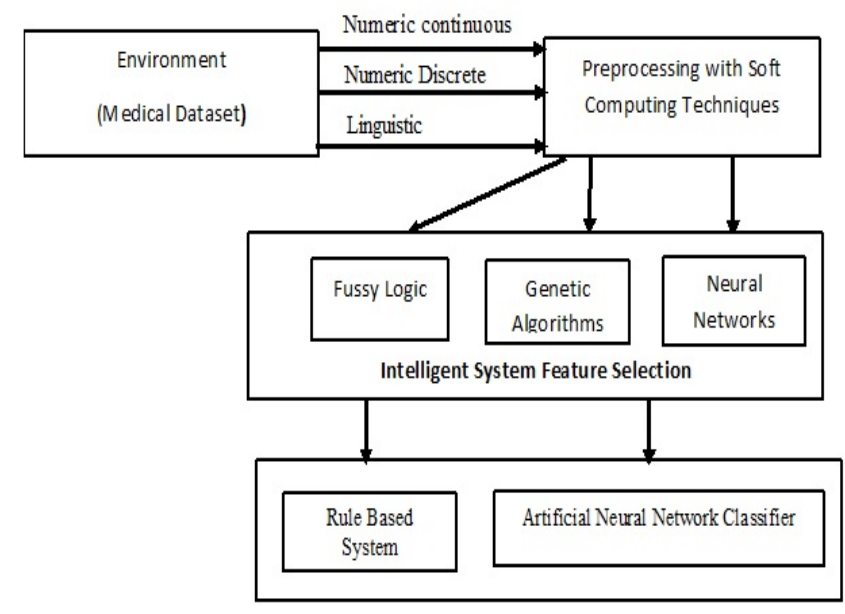

Fig.3. Modern Intelligent pattern Classification System

The datasets, methods \& techniques, attribute or indicator, assessment measures \& classification accuracies of pervious are shown in each column, respectively.

TABLE I. LISTOF ATTRIBUTE AND SIZE OF DATASET

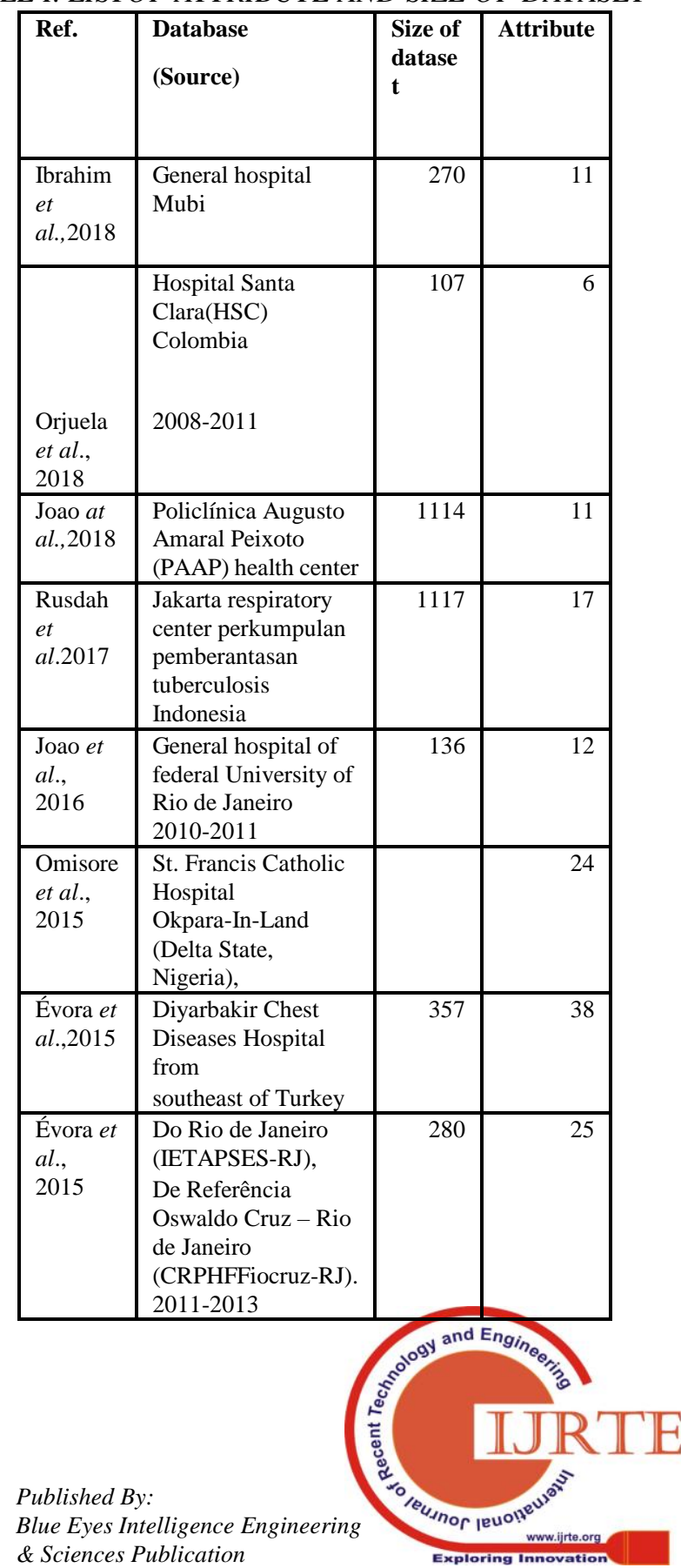




\begin{tabular}{|l|l|r|r|}
$\begin{array}{l}\text { Winark } \\
\text { o } \text { et al., } \\
2015\end{array}$ & $\begin{array}{l}\text { Jakarta respiratory } \\
\text { center of tuberculosis } \\
\text { from 2010-2014 }\end{array}$ & 1170 & 17 \\
\hline $\begin{array}{l}\text { Évora } \text { et } \\
\text { al., } \\
2015\end{array}$ & $\begin{array}{l}\text { KIMS Hospital, } \\
\text { Bangalore }\end{array}$ & 700 & 11 \\
\hline $\begin{array}{l}\text { Errison } \\
\text { et al., } \\
2013\end{array}$ & $\begin{array}{l}\text { IDT/HUCFF/UFRJ, } \\
\text { 2001- 2008 }\end{array}$ & 972 & 19 \\
\hline $\begin{array}{l}\text { Uçar } \text { et } \\
\text { al., } \\
2013\end{array}$ & $\begin{array}{l}\text { Private Health Clinic } \\
\text { in Istanbul }\end{array}$ & 503 & 20 \\
\hline $\begin{array}{l}\text { Asha } \text { et } \\
\text { al., } \\
2010\end{array}$ & A state & & \\
\hline
\end{tabular}

Table I. summarized all the experiments' result. It showed that the comparison of accuracy, trained algorithms which classifiers could provide better performance. Besides, according to this fact, the aim of this review by comparing different method and techniques, which trained algorithm more accurate on different dataset. A graph showing in detail the comparison of accuracy, trained algorithms has been shown in fig 4.

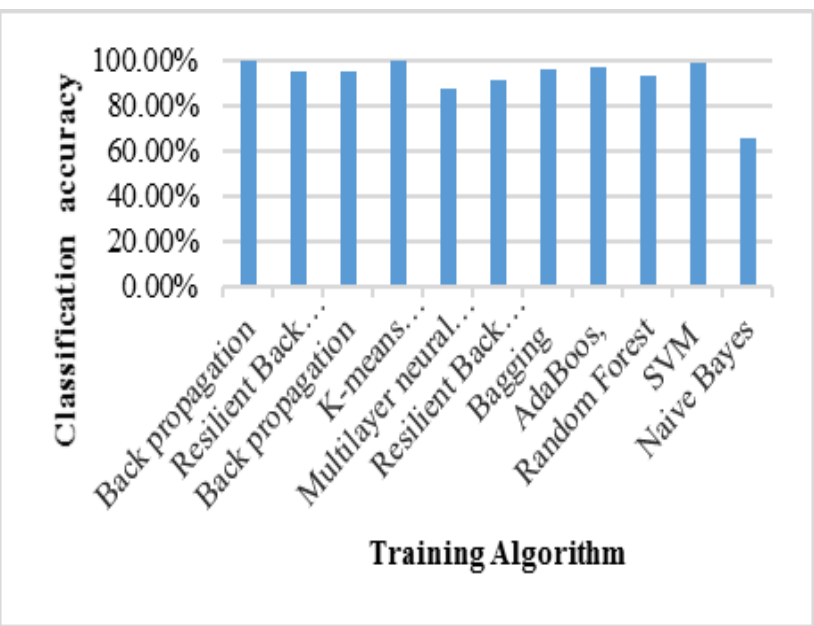

\section{A. Fig .4. Soft Computing Techniques Accuracy}

\section{A. Comparison of Different Classification Classifiers' Accuracy}

There have been a few studies reported concentrating on pulmonary tuberculosis disease detection problem using artificial neural network system structures with respect to other clinical determination issues. These examinations have connected distinctive neural systems structures to the different chest diseases determination problem applying their different dataset [14], [16], [36]. In view of the different dataset used by the researcher, the immediate correlation of the outcomes was unimaginable. In this way, these neural systems were thought about utilizing the equivalent dataset which comprises of various highlights. So we can easily say that MLNN, Levenberg- Marquardt training as shown in Table III [16], [26], and [36].

Researchers compared several methods in order to study which method obtained the highest accuracy in diagnosing tuberculosis. The results showed that various intelligent system methods used for diagnosing tuberculosis are summarized in Table II.

\section{TABLE II. LIST OF METHODS, TECHNIQUES, TRAINED ALGORITHM AND CLASSIFICATION ACCURACY}

\begin{tabular}{|c|c|c|c|}
\hline Ref. & $\begin{array}{l}\text { Methods \& } \\
\text { Techniques }\end{array}$ & $\begin{array}{l}\text { Training } \\
\text { Algorithm }\end{array}$ & $\begin{array}{l}\text { Classificatio } \\
\text { n } \\
\text { accuracy }(\%)\end{array}$ \\
\hline $\begin{array}{l}\text { Ibrahim et } \\
\text { al.,2018 }\end{array}$ & $\begin{array}{l}\text { Adaptive } \\
\text { neuro-fuzzy, }\end{array}$ & back propagation & 99.6 \\
\hline $\begin{array}{l}\text { Orjuela } e t \\
\text { al }, 2018\end{array}$ & $\begin{array}{l}\text { Artificial } \\
\text { neural networks }\end{array}$ & Back propagation & 95 \\
\hline $\begin{array}{l}\text { Joao } \text { et al } \\
\text {,2018 }\end{array}$ & $\begin{array}{l}\text { Artificial neural } \\
\text { networks }\end{array}$ & $\begin{array}{l}\text { Resilient Back } \\
\text { propagation }\end{array}$ & 95 \\
\hline $\begin{array}{l}\text { Rusdah et } \\
\text { al.2017 }\end{array}$ & $\begin{array}{l}\text { Discretization, } \\
\text { Rough set }\end{array}$ & SVM - C5.0 & 97.59 \\
\hline $\begin{array}{l}\text { Joao et al., } \\
2016\end{array}$ & $\begin{array}{l}\text { ANN ,Multilayer } \\
\text { perceptron }\end{array}$ & $\begin{array}{l}\text { support vector } \\
\text { machine }\end{array}$ & 88 \\
\hline $\begin{array}{l}\text { Zakhmi, } \\
2016\end{array}$ & $\begin{array}{l}\text { Genetic algorithm } \\
\text { and Neural network } \\
\text { backwash }\end{array}$ & $\begin{array}{l}\text { K-means } \\
\text { Clustering, } \\
\text { Support Vector } \\
\text { Machine }\end{array}$ & 99.73 \\
\hline $\begin{array}{l}\text { Omisore } e t \\
\text { al., } 2015\end{array}$ & $\begin{array}{l}\text { Genetic-Neuro-Fuz } \\
\text { zy Inferential }\end{array}$ & $\begin{array}{l}\text { Back-propagatio } \\
n \text { algorithm }\end{array}$ & 70 \\
\hline $\begin{array}{l}\text { Évora } e t \\
\text { al.,2015 }\end{array}$ & $\begin{array}{l}\text { Artificial neural } \\
\text { networks }\end{array}$ & $\begin{array}{l}\text { multilayer neural } \\
\text { network (MLNN) }\end{array}$ & 91 \\
\hline $\begin{array}{l}\text { Évora } e t \\
\text { al., } 2015\end{array}$ & $\begin{array}{l}\text { Feed forward } \\
\text { Multilayer } \\
\text { Perceptron (MLP) }\end{array}$ & $\begin{array}{l}\text { Resilient Back } \\
\text { propagation }\end{array}$ & 91.3 \\
\hline $\begin{array}{l}\text { Winarko } \\
\text { et al., } \\
2015\end{array}$ & Ensemble & $\begin{array}{l}\text { SVM, } \\
\text { C4.5, Naive } \\
\text { Bayes and Back } \\
\text { propagation }\end{array}$ & $\begin{array}{ll}70.67, & \\
66,93, & \\
65.58, & \\
& 63.73\end{array}$ \\
\hline $\begin{array}{l}\text { Évora } e t \\
a l ., 2015\end{array}$ & $\begin{array}{l}\text { K-Means } \\
\text { Clustering }\end{array}$ & SVM, & 98.7 \\
\hline $\begin{array}{l}\text { Uçar } \text { et } \\
\text { al., } 2013\end{array}$ & $\begin{array}{l}\text { ANFIS and rough } \\
\text { sets }\end{array}$ & $\begin{array}{l}\text { ANFIS Rough } \\
\text { sets }\end{array}$ & $\begin{array}{l}97 \\
92\end{array}$ \\
\hline $\begin{array}{l}\text { Asha } e t \\
\text { al., } 2010\end{array}$ & $\begin{array}{l}\text { Supervised } \\
\text { Machine Learning } \\
\text { (ML) }\end{array}$ & $\begin{array}{l}\text { Bagging and } \\
\text { AdaBoos, } \\
\text { Random Fores }\end{array}$ & $\begin{array}{l}96.00, \\
97.00\end{array}$ \\
\hline
\end{tabular}

TABLE III. COMPARISON OF METHODS \& TECHNIQUES' WITH ACCURACY ON TRAINING DATASETS

\begin{tabular}{|c|c|c|c|}
\hline $\begin{array}{ll}\text { Methods } \quad \& \\
\text { Techniques }\end{array}$ & $\begin{array}{l}\text { Usage of } \\
\text { training } \\
\text { dataset } \\
(\%)\end{array}$ & $\begin{array}{l}\text { Accuracy } \\
\text { on } \\
\text { percentage } \\
(\%) \\
\end{array}$ & Ref. \\
\hline $\begin{array}{l}\text { Rough Set, } \\
\text { discretization } \\
\text { function }\end{array}$ & 70.00 & 97.59 & $\begin{array}{l}\text { Rusdah et } \\
\text { al.2017 }\end{array}$ \\
\hline ANFIS & 66.70 & 99.60 & $\begin{array}{l}\text { Ibrahim et } \\
\text { al.,2018 }\end{array}$ \\
\hline
\end{tabular}




\begin{tabular}{|l|l|l|l|}
\hline MLP & 75.00 & 95.00 & $\begin{array}{l}\text { Joao at } \\
\text { al.,2018 }\end{array}$ \\
\hline $\begin{array}{l}\text { k-means } \\
\text { algorithm }\end{array}$ & 50.90 & 91.30 & $\begin{array}{l}\text { Errison et } \\
\text { al., 2013 }\end{array}$ \\
\hline $\begin{array}{l}\text { MLP ,Support } \\
\text { Vector } \\
\text { Machine(SVM) }\end{array}$ & 75.00 & 88.00 & $\begin{array}{l}\text { Joao } \text { et al., } \\
2016\end{array}$ \\
\hline $\begin{array}{l}\text { Artificial } \\
\text { Immune } \\
\text { Recognition } \\
\text { Algorithm }\end{array}$ & 80.00 & 99.14 & $\begin{array}{l}\text { Shamshirb } \\
\text { and et al., } \\
2014\end{array}$ \\
\hline
\end{tabular}

The researcher has attempted to show that an instance selection procedure is assumed [12], [34]. Therefore the primary goal of splitting the data set was to share the most common similar characteristics and differentiate a cluster algorithm.

Early diagnosis of pulmonary tuberculosis was used in their 2017 TB diagnosis study using ensemble method [12].They used 1170 samples with seventy features classified by incorporating a C5.0 \& SVM. This modified Moran's approach resulted in the highest learning rate classification accuracy (a) with a value of $0.8[12]$. As shown in Table II, the method was $(84.54 \%)$ accurate, $(84.24 \%)$ sensitive and $(85.54 \%)$ specificity [14]. By applying artificial neural network model support to easily detect active pulmonary tuberculosis disease. [14] was the focus of their 2018 finding. The newly developed Multilayer Perceptron (MLP) is viewed for various diagnostic purposes as a potential algorithm and they got viable TB screening performance of $95 \%$ as shown in fig 5 . The two methods like artificial neural network and genetic algorithms are certainly proved as a very successful diagnostic model [27].

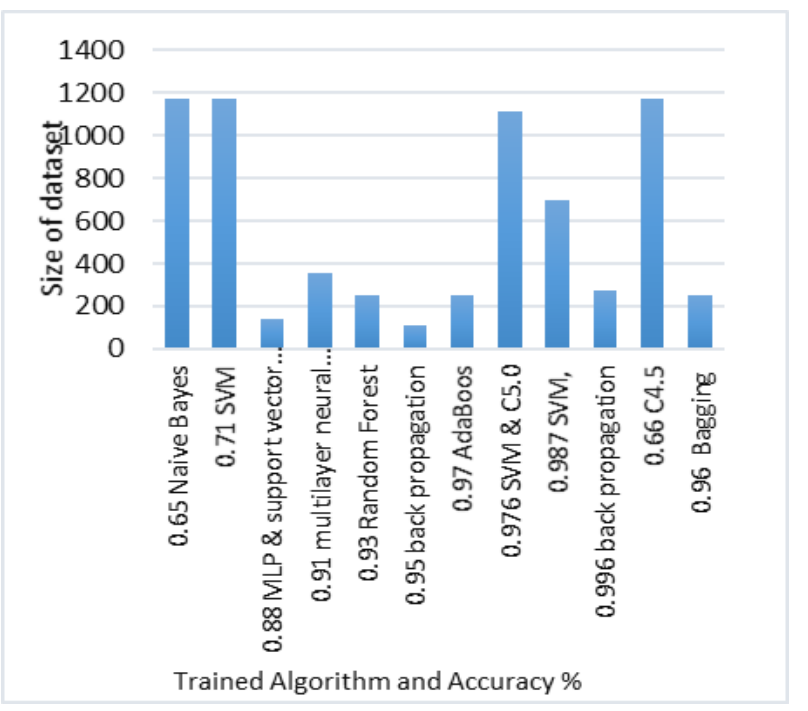

\section{FIG 5. COMPARISON THE SIZE OF DATASET WITH CLASSIFICATION ACCURACY (\%)}

\section{B. Performance of analysis of testing phase result on different models using cross- validation}

There are few studies related to intelligent system for diagnosis of tuberculosis using different soft computing techniques. Most of these studies have high classification accuracy rates. These studies used cross- validation to evaluate the performance of the trained and test dataset.

Cross-validation is a measurable approach utilized in this analysis to assess the execution of learning algorithms and performance of on an unknown dataset of a predictive model. Consequently, the informational collections utilized in research are isolated into a few sub-sets of equivalent size applying cross-validation. On certain subsets known as training sets, the learning model is then learned. 16], [17], [34]. Depending on the number of partitioned subsets. For 10-fold cross validation, the researcher tests K-fold cross-validation and have got 10 results as shown in Table III of various researcher experiments, for training models, different 10 tests are considered for 10 -fold cross validation [16], [17], [18], [34], and [36].

Describes the performance achieved as prognostic models for pulmonary tuberculosis (PTB) using alternative computational intelligence methods. Between smear negative PTB cases, the world health organization algorithms, the standard reported of clinical work and chest analysis shows sensitivity values ranged from $(58.8 \%)$ to $(95 \%)$ and between $(79.4 \%)$ and $(98 \%)$. Thus, the current model achieves similarly to other scores that include CXR only by using signs and symptoms. With regard to MLP-based PTB screening models, the current clinical score using [14]. Twelve variables are similar in accuracy $(88 \%)$ to those reported by [42]. (19 variables and 93.3\% accuracy), [14] (11 variables and $95 \%$ accuracy).

Approximate probability of active pulmonary tuberculosis was provided by the output of the Rough set, SVM. To train the neural networks, the study used a 10-fold cross-validation procedure and accuracy of the diagnosis result report approximately (84.54) [12] the study performing the classification procedure for artificial immune system structure for chest diseases, 10- Fold cross validation method was used to estimate the performance of the Artificial Intelligence System used and MLNN was accurate with a single-hidden layer $(90.48 \%)$, while the precision was hidden $(93.84 \%)$ with two layers., hidden layers are therefore the best result of the accuracy of the classification.

Because there are 257 patient data and 100 healthy data in the entire dataset, there were 36 samples in each fold. Of these 36 samples, 26 were taken from records of patients, while the other 10 were healthy individuals. The classification algorithm was trained and tested 10 times. In each case, one of the folds is taken as test data and the remaining folds are for the training data as shown in Table IV [18] 
Table iv. Comparison of classifier using cross-validation, accuracies, sensitivity\& specificity.

\begin{tabular}{|c|c|c|c|c|}
\hline \multirow[t]{2}{*}{$\begin{array}{l}\text { Study } \\
\text { Author }\end{array}$} & \multirow[t]{2}{*}{ Classifier } & \multicolumn{3}{|c|}{ T esting performance } \\
\hline & & $\begin{array}{l}\text { Accurac } \\
\text { y (\%) }\end{array}$ & $\begin{array}{l}\text { Sensitivi } \\
\text { ty (\%) }\end{array}$ & $\begin{array}{l}\text { Specifici } \\
\text { ty (\%) }\end{array}$ \\
\hline $\begin{array}{l}\text { Joao at } \\
\text { al.,2018 }\end{array}$ & $\begin{array}{l}\text { Multiple } \\
\text { layer } \\
\text { perception }\end{array}$ & 95.00 & 92.00 & 58.00 \\
\hline $\begin{array}{l}\text { Orjuela et } \\
\text { al., } 2018\end{array}$ & $\begin{array}{l}\text { MLP, } \\
\text { SOM }\end{array}$ & 95.00 & 97.00 & 71.00 \\
\hline $\begin{array}{l}\text { B adnjevic } \\
\text { et al.,2017 }\end{array}$ & $\begin{array}{l}\text { fuzzy } \\
\text { logic }\end{array}$ & 97.00 & 97.26 & 70.74 \\
\hline \multirow{2}{*}{$\begin{array}{l}\text { Rusdah et } \\
\text { al.2017 }\end{array}$} & \multirow{2}{*}{$\begin{array}{l}\text { C4.5, } \\
\text { Naive } \\
\text { Bayes, } \\
\text { SVM }\end{array}$} & 84.54 & 85.24 & 85.24 \\
\hline & & 83.31 & 84.46 & 84.46 \\
\hline $\begin{array}{l}\text { Joao et al. } \\
2016\end{array}$ & $\begin{array}{l}\text { MLP } \\
\text { support } \\
\text { vector } \\
\text { machine } \\
\end{array}$ & 88.00 & $\begin{array}{l}95.00 \\
86.00\end{array}$ & $\begin{array}{l}80.00 \\
60.00\end{array}$ \\
\hline $\begin{array}{l}\text { Omisore } \\
\text { et al., } \\
2015\end{array}$ & $\begin{array}{l}\text { Back- } \\
\text { propagatio } \\
\text { n } \\
\text { algorithm }\end{array}$ & 70.00 & 60.00 & \\
\hline $\begin{array}{l}\text { Evora et } \\
\text { al. } 2015\end{array}$ & $\begin{array}{l}\text { forward- } \\
\text { propagatio } \\
\mathrm{n} \\
\text { algorithm }\end{array}$ & 91.3 & 95.15 & 85.47 \\
\hline $\begin{array}{l}\text { Shamshirb } \\
\text { and et al., } \\
2014\end{array}$ & $\begin{array}{l}\text { fuzzy } \\
\text { logic }\end{array}$ & 99.14 & 87.00 & 86.12 \\
\hline $\begin{array}{l}\text { Asha et } \\
a l ., 2010\end{array}$ & $\begin{array}{l}\text { Random } \\
\text { Forest }\end{array}$ & 93.00 & 97.00 & 96.00 \\
\hline
\end{tabular}

Summarization of the above table IV. The result showed to evaluate the performance of the pulmonary tuberculosis diagnosis predictive models using 10 -fold cross validation. The intelligent system's performance, classification accuracy, sensitivity, specificity and usefulness were examined using real medical data for the experiments.

Another researcher used the patterns of inputs to form 14 distinct parameters divided into two group's major demographic variables and findings of constitutional symptoms as shown in Table I. The table above showed that using 10 fold cross validation such intelligent system techniques will help medical experts to improve the quality of healthcare services they provide.

\section{CONCLUSION}

This study's main objective is to identify, categorize and evaluate the importance of various soft computing techniques for diagnosing and predicting diseases. This review's main findings are summarized as follows:

Several literatures gathered from many sources that are classified through the size of dataset used for training and testing algorithm, attributes (variables), data preprocessing techniques and methods, comparison of classification accuracy used for tuberculosis diagnosis analysis. From those selected literatures that have been reviewed. We presume that, utilization of soft computing method in medicinal finding have been revealed for PTB diagnosis and prediction. Besides that several researcher observed artificial neural network and genetic algorithm are connected to acquire the upgraded estimation of SVM and artificial neural network (ANN). Fuzzy logic and neuro fuzzy approach support rules to design expert system. The tenets are depicted as on the off chance that, at that point k-nearest Neighbor clustering techniques are embraced to locate the significant parameters of the diseases. Further, it is expressed that the improvement in pulmonary tuberculosis detection with clinical practice is laid in the structuring of insightful system arranged to maladies side effects. Subsequently likewise, insight intelligent system tools can be seen as a potential detection mechanism and for tuberculosis as well as for many life - threatening diseases. This review work can be extended using other soft computing techniques and also for other diseases \& finally for a complete medical expert system.

\section{REFERENCES}

1. McBroom, K., "Litigation as TB Rights Advocacy: A New Delhi Case Study," Health and human rights, 2016, vol. 18(1), p.69.

2. Orjuela-Cañón, A.D., Mendoza, J.E.C., García, C.E.A. and Vela, E.P.V., "Tuberculosis diagnosis support analysis for precarious health information systems," Computer methods and programs in biomedicine, 2018, vol. 157, pp.11-17.

3. You, M., Liu, Z., Chen, C., Liu, J., Xu, X.H. and Qiu, Z.M., "Cough detection by ensembling multiple frequency subband features,' Biomedical Signal Processing and Control, 2017, vol. 33, pp.132-140.

4. Dye, C., Bassili, A., Bierrenbach, A.L., Broekmans, J.F., Chadha, V.K., Glaziou, P., Gopi, P.G., Hosseini, M., Kim, S.J., Manissero, D. and Onozaki, I., Measuring tuberculosis burden, trends, and the impact of control programmes. The Lancet infectious diseases, 2008, vol. 8(4), pp.233-243.

5. Zwerling, A., Joshi, R., Kalantri, S.P., Dakshinamoorthy, G., Reddy, M.V., Benedetti, A., Schwartzman, K., Menzies, D. and Pai, M., "Trajectories of tuberculosis-specific interferon-gamma release assay responses among medical and nursing students in rural India," Journal of epidemiology and global health, 2013, vol. 3(2), pp.105-117.

6. Winarko, E. and Wardoyo, R., "Preliminary diagnosis of pulmonary tuberculosis using ensemble method," In Data and Software Engineering (ICoDSE), 2015, IEEE International Conference on, 2015, vol. pp. 175-180.

7. Pachange, S., Joglekar, B. and Kulkarni, P., "An ensemble classifier approach for disease diagnosis using Random Forest," In India Conference (INDICON), 2015 Annual IEEE, 2015, vol. pp. 1-5. IEEE

8. Zhang, Z.X., Sng, L.H., Yong, Y., Lin, L.M., Cheng, T.W., Seong, N.H. and Yong, F.K., "Delays in diagnosis and treatment of pulmonary tuberculosis in AFB smear-negative patients with pneumonia," The International Journal of Tuberculosis and Lung Disease, 2017, vol. 21(5), pp.544-549.

9. Subbaram Naidu, D. "Soft computing and intelligent systems design theory, tools and applications, FO Karry and C. De Silva, Pearson, Addison-Wesley, New York, NY, 2004." International Journal of Robust and Nonlinear Control: IFAC-Affiliated Journal 16, no. 11 (2006): 548-551

10. Sarkar, Bikash Kanti. "Improving disease diagnosis by a new hybrid model." New Horizons in Translational Medicine 4, no. 1-4 (2017) 31-47. World Health Organization, "Global tuberculosis report 2015," World Health Organization, 2015.

11. Rusdah, Edi Winarko, and Retantyo Wardoyo. "Predicting The Suspect of New Pulmonary Tuberculosis Case using SVM, C5. 0 and Modified Moran's I." INTERNATIONAL JOURNAL OF COMPUTER SCIENCE AND NETWORK SECURITY 17, no. 12 (2017): 164-171

12. Omisore, Mumini Olatunji, Oluwarotimi Williams Samuel, and Edafe John Atajeromavwo. "A Genetic-Neuro-Fuzzy inferential model for diagnosis of tuberculosis." Applied Computing and Informatics 13, no. 1 (2017): 27-37. 
13. João Filho, B. de O., José Manoel de Seixas, Rafael Galliez, Basilio de Bragança Pereira, Fernanda C. de Q Mello, Alcione Miranda dos Santos, and Afranio Lineu Kritski. "A screening system for smear-negative pulmonary tuberculosis using artificial neural networks." International Journal of Infectious Diseases 49 (2016): 33-39.

14. Badnjevic, Almir, Lejla Gurbeta, Mario Cifrek, and Leandro Pecchia. "Pre-classification process symptom questionnaire based on fuzzy logic for pulmonary function test cost reduction." In CMBEBIH 2017, pp. 608-616. Springer, Singapore, 2017.

15. Évora, L. H. R. A., J. M. Seixas, and A. L. Kritski. "Artificial neural network models for diagnosis support of drug and multidrug resistant tuberculosis." In 2015 Latin America Congress on Computational Intelligence (LA-CCI), pp. 1-5. IEEE, 2015.

16. Ashadevi, B., Selvi, P.M. and Revathi, B.S., 2017, "An Effective Diagnosis of Pulmonary Tuberculosis using K-Means Clustering and ANFIS," Scholars Journal of Engineering and Technology (SJET), vol. 5(8) pp.427-439.

17. Er, Orhan, Nejat Yumusak, and Feyzullah Temurtas. "Diagnosis of chest diseases using artificial immune system." Expert Systems with Applications 39, no. 2 (2012): 1862-1868.

18. Sarin, Rohit, Vikram Vohra, U. K. Khalid, Prem Prakash Sharma, Vineet Chadha, and M. A. Sharada. "Prevalence of pulmonary tuberculosis among adults in selected slums of Delhi city." Indian Journal of Tuberculosis 65, no. 2 (2018): 130-134.

19. Jiang, Fei, Yong Jiang, Hui Zhi, Yi Dong, Hao Li, Sufeng Ma, Yilong Wang, Qiang Dong, Haipeng Shen, and Yongjun Wang. "Artificial intelligence in healthcare: past, present and future." Stroke and vascular neurology 2, no. 4 (2017): 230-243.

20. Asha, T., S. Natarajan, and K. N. B. Murthy. "Diagnosis of tuberculosis using ensemble methods." In 2010 3rd International Conference on Computer Science and Information Technology. 2010.

21. Carlsson, Christer, and Pirkko Walden. "Intelligent Systems and Soft Computing: Minitrack Introduction." In Proceedings of the Proceedings of the 37th Annual Hawaii International Conference on System Sciences (HICSS'04)-Track 3-Volume 3, p. 30073. IEEE Computer Society, 2004.

22. Sarin, Rohit, Vikram Vohra, U. K. Khalid, Prem Prakash Sharma, Vineet Chadha, and M. A. Sharada. "Prevalence of pulmonary tuberculosis among adults in selected slums of Delhi city." Indian Journal of Tuberculosis 65, no. 2 (2018): 130-134.

23. Jiang, Fei, Yong Jiang, Hui Zhi, Yi Dong, Hao Li, Sufeng Ma, Yilong Wang, Qiang Dong, Haipeng Shen, and Yongjun Wang. "Artificial intelligence in healthcare: past, present and future." Stroke and vascular neurology 2, no. 4 (2017): 230-243.

24. Bhatia, Ajay, Vijay Mago, and Rajeshwar Singh. "Use of soft computing techniques in medical decision making: A survey." In 2014 International Conference on Advances in Computing, Communications and Informatics (ICACCI), pp. 1131-1137. IEEE, 2014.

25. Fojnica, A., Osmanović, A. and Badnjević, A., "Dynamical model of Tuberculosis-Multiple Strain Prediction based on artificial neural network," In Embedded Computing (MECO), 2016 5th Mediterranean Conference on, 2016, vol. pp. 290-293. IEEE.

26. Zakhmi, R., "Tuberculosis Disease Forecasting among Indian Patients," International Journal on Recent and Innovation Trends in Computing and Communication, 2016, vol. 4(8), pp.180-183.

27. Sharma, R. and Kochher, R., "Fuzzy decision support system for tuberculosis detection," In Communication and Signal Processing (ICCSP), 2017 International Conference on, 2017, vol. pp. 2001-2005. IEEE.

28. Karray, F., Karray, F.O. and De Silva, C.W. "Soft computing and intelligent systems design: theory, tools, and applications," Pearson Education., Addison-Wesley, New York, NY, 2004. International Journal of Robust and Nonlinear Control: IFAC-Affiliated Journal; 2004, vol. 16(11):548-51.

29. Karray, F., Karray, F.O. and De Silva, C.W., 2004. "Soft computing and intelligent systems design: theory, tools, and applications," Pearson Education.

30. Uçar, T., Karahoca, A. and Karahoca, D., 2013. "Tuberculosis disease diagnosis by using adaptive neuro fuzzy inference system and rough sets," Neural Computing and Applications, vol. 23(2), pp.471-483.

31. Gambhir, S., Malik, S.K. and Kumar, Y., "Role of soft computing approaches in healthcare domain: a mini review," Journal of medical systems, 2016, vol. 40(12), p.287.

32. Orjuela-Cañón, A.D., Mendoza, J.E.C., García, C.E.A. and Vela, E.P.V., "Tuberculosis diagnosis support analysis for precarious health information systems," Computer methods and programs in biomedicine, 2018, vol. 157, pp.11-17.

33. e Souza, J.B.D.O., Sanchez, M., de Seixas, J.M., Maidantchik, C., Galliez, R., Moreira, A.D.S.R., da Costa, P.A., Oliveira, M.M., Harries, A.D. and Kritski, A.L., "Screening for active pulmonary tuberculosis: Development and applicability of artificial neural network models," Tuberculosis, 2018, vol. 111, pp.94-101.

34. Alves, E., Souza Filho, J.B. and Kritski, A.L., "An ensemble approach for supporting the respiratory isolation of presumed tuberculosis inpatients," Neurocomputing, 2019, vol. 331, pp.289-300.

35. Dos Santos Alves, E., Souza Filho, J.B., Galliez, R.M. and Kritski, A., "Specialized MLP classifiers to support the isolation of patients suspected of pulmonary tuberculosis," IEEE In Computational Intelligence and 11th Brazilian Congress on Computational Intelligence (BRICS-CCI \& CBIC), 2013 BRICS Congress on, 2013, vol. pp. $40-45$

36. Chakraborty, B. and Chakraborty, G. "Soft computing techniques for intelligent classification system: a case study," In Soft Computing Methods in Industrial Applications, 1999. SMCia/99. Proceedings of the 1999 IEEE Midnight-Sun Workshop on, 1999, vol. pp. 16-21.

37. Sikchi, S.S., Sikchi, S. and Ali, M.S., "Artificial intelligence in medical diagnosis," International Journal of Applied Engineering Research, 2012, vol. 7(11)

38. Bhatia, A., Mago, V. and Singh, R., "Use of soft computing techniques in medical decision making: A survey," IEEE in Advances in Computing, Communications and Informatics (ICACCI, 2014 International Conference on, 2014. Vol. pp. 1131-113.

39. Natarajan, S. and Murthy, K.N.B., "A Data Mining Approach to the Diagnosis of Tuberculosis by Cascading Clustering and Classification," 2011, arXiv preprint arXiv: 1108.1045.

40. Tyagi, P.K., Gupta, N.K. and Gupta, S., "Diagnosis of Pulmonary Tuberculosis using fuzzy Inference System,” IEEE In Computationa Intelligence on Power, Energy and Controls with their Impact on Humanity (CIPECH), 2016 Second International Innovative Applications of , 2016, vol. pp. 3-7.

41. dos Santos Alves, E., Souza Filho, J.B., Galliez, R.M. and Kritski, A., "Specialized MLP classifiers to support the isolation of patients suspected of pulmonary tuberculosis," IEEE In Computational Intelligence and 11th Brazilian Congress on Computational Intelligence (BRICS-CCI \& CBIC), 2013 BRICS Congress on , 2013, vol. pp. $40-45$

\section{AUTHORS PROFILE}

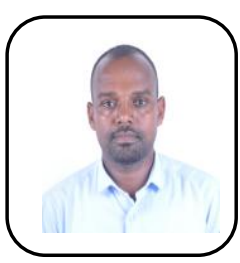

Siraj Sebhatu. He received his bachelor's degree (BSc) in Information Technology and MSc in Information Science and health Informatics from Addis Ababa University, Ethiopia in 2015. He is a Ph.D. student at Department of Computer Science and Engineering, School of Engineering \&Technology and Sharda University. His research interests are Artificial Intelligent, Soft computing, machine learning data and data mining.

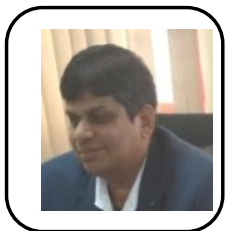

Ashok Kumar Sahoo completed his $\mathrm{PhD}$ in Computer Science \& Engineering from Sharda University. His topic of research was "Computer Recognition of Indian Sign Language". His publications include more than fifteen papers in International Refereed Journals, presented three papers in International conferences. His research interests include Pattern Recognition, Machine Learning, Neural Networks and Intelligent systems. He has more than 18 years of teaching experience in various technical Institutions. He has been working in this University since November 2003. He is currently working as an Associate Professor in Computer Science \& Engineering Department. He is also actively involved in various research and administrative activities of the University. 
Pooja has done her Ph. D. from Dr B R Ambedker National Institute of Technology - Jalandhar, PB. Presently she is working as Associate Professor in Department of Computer Science \& Engineering, School of Engineering \&Technology, Sharda University, Greater Noida, Uttar Pradesh, India. She is the life member of Indian Unit for Pattern Recognition and Artificial Intelligence (IUPRAI). She is also life member of Advanced Computing \& Communications Society i.e. ACCS, Indian Institute of Science, Bangalore, India and Associate Member of Universal Association of Computer and Electronics Engineers i.e. UACEE (http://uacee.org), The IRED. She is also Editorial Board Member of International Journal of Computer Science Trends and Technology (IJCST). She has guided many PG projects and Ph.D. theses and she has published 60 research papers in Journals and conferences. 